\title{
aprovechamiento hidroeléctrico del río Eume
}

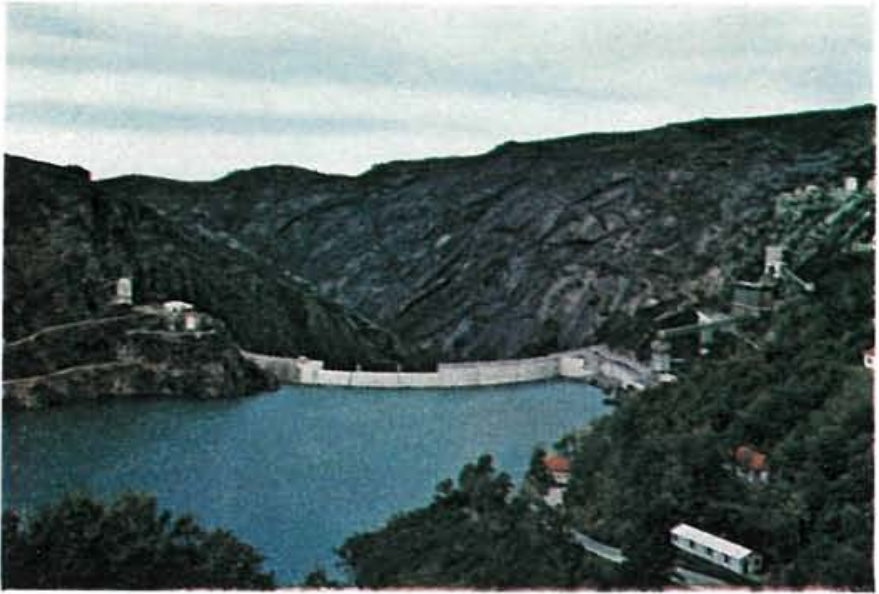

En la provincia de La Coruña, junto a la desembocadura del río Eume, y en las proximidades del pueblo de Puentedeume, se ha realizado el aprovechamiento hidroeléctrico de dicho río, formado, en cuestión, por tres elementos básicos una presa de embalse de doble curvatura, de $103 \mathrm{~m}$ de altura una conducción forzada, integrada por un túnel de $2.839 \mathrm{~m}$ de longitud y dos tuberías de 310 ; y una central, equipada con dos grupos de $75.000 \mathrm{CV}$

\section{Emplazamiento de la presa}

El tramo del río Eume elegido para formar el salto proyectado está situado aguas abajo de Puentes de García Rodríguez, presentando en esta parte el río acusada pendiente por encontrarse en esa zona intermedia exenta de acarreos importantes, $y$, por lo tanto, propicia para construir una presa con poca excavación de cimentación.

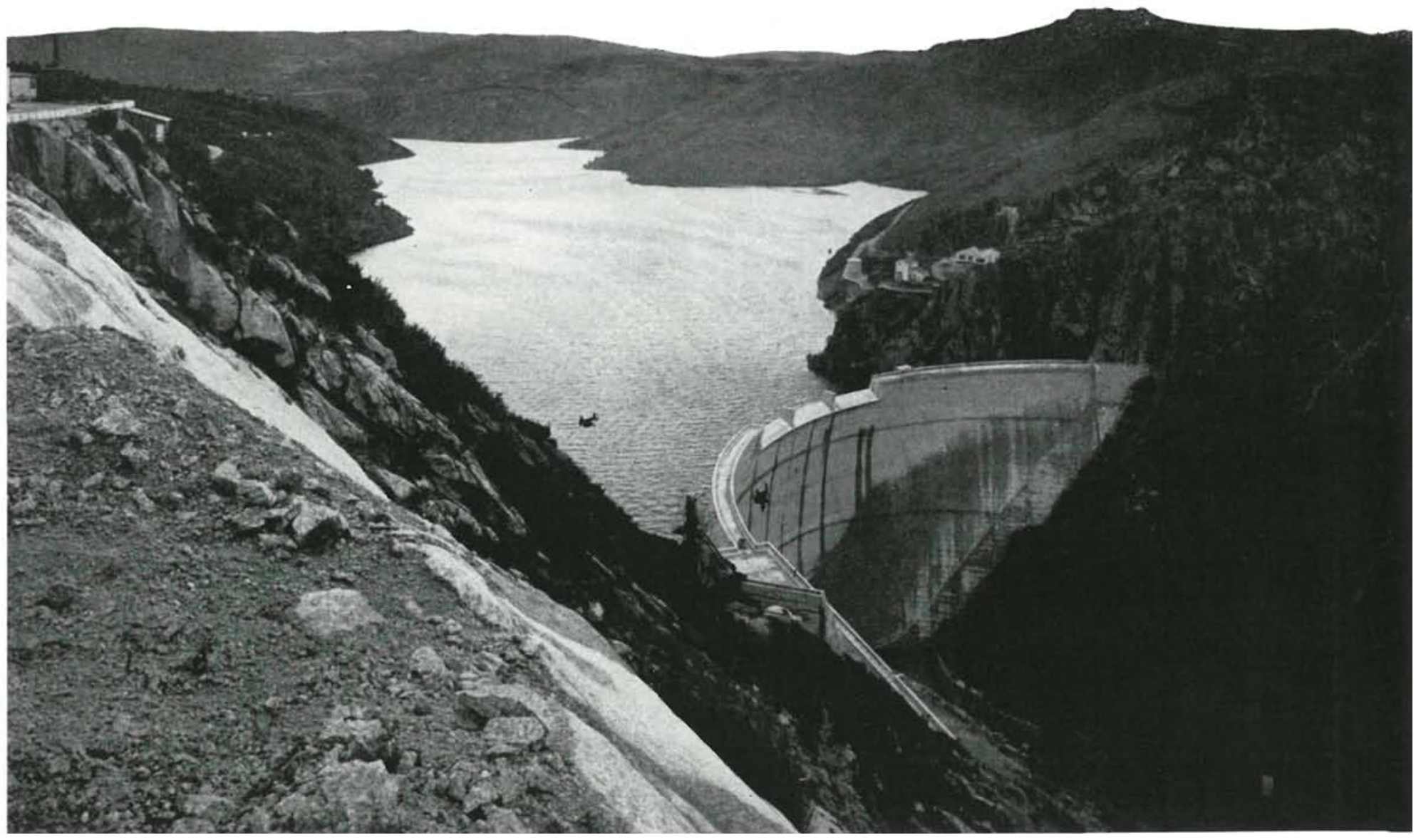




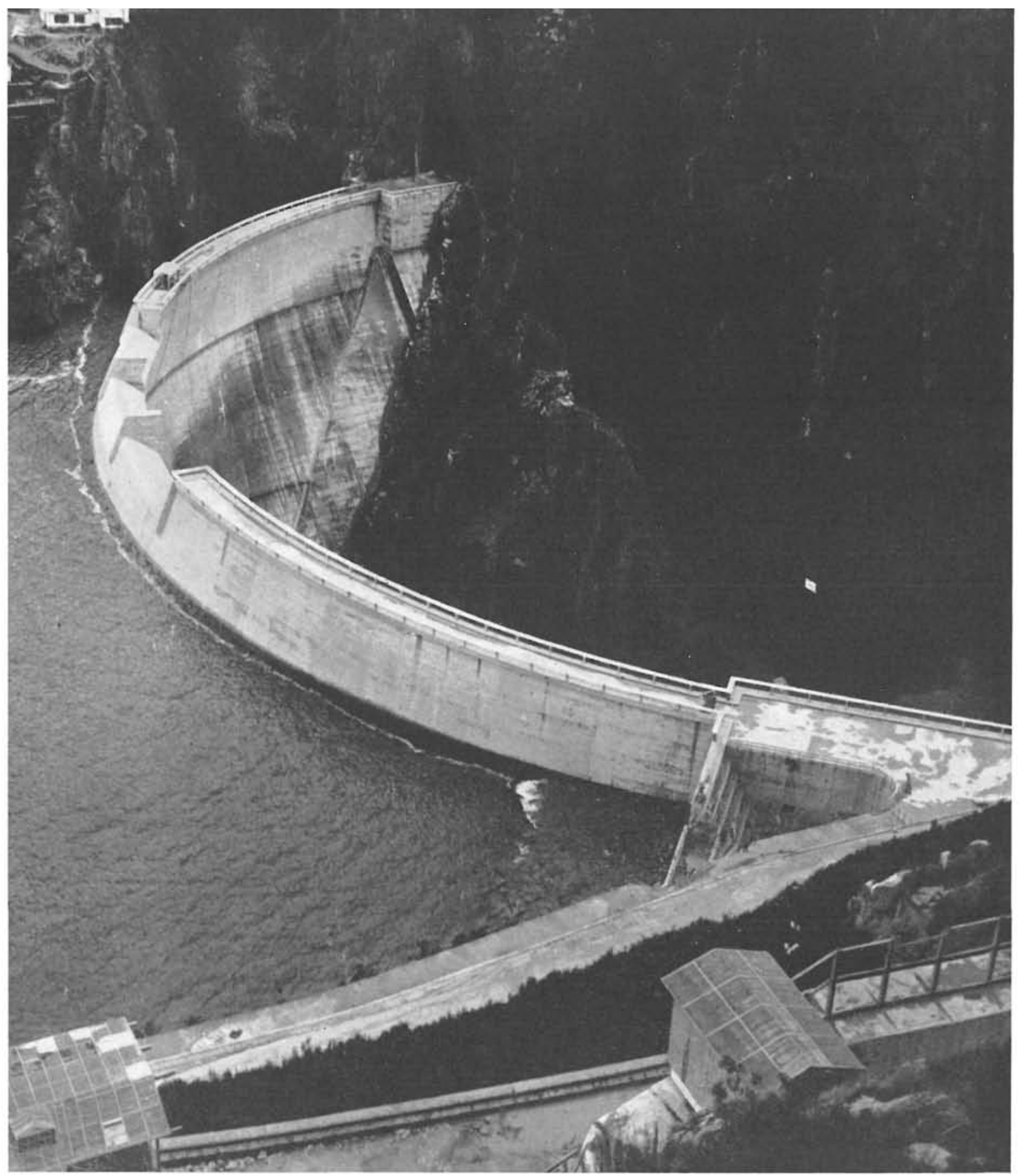

Dentro de este tramo, el lugar elegido para el emplazamiento de la presa, por reunir las mejores condiciones topográficas, ofrecía un terreno constituído por rocas cristalofílicas, predominantemente pizarrosas, con estratos próximos a la vertical y sensiblemente normales al cauce del río en ese tramo. Los lechos pizarrosos contenían algas que inducian a asignar al paquete de estratos la edad cámbrica, sin que sea muy segura su clasificación, desde luego paleozoica.

En cambio, aguas arriba de la zona de emplazamiento el valle se ensancha y no ofrecía buenas condiciones topográficas; aguas abajo estas condiciones eran más favorables, pero no así las geológicas, por penetrar en la zona de granito, cuya naturaleza, menos resistente, motiva el grado más avanzado de la erosión en sus diaclasas, siendo a este respecto bien elocuente el gran liso que se presenta en la ladera derecha verdadero espejo de falla, que nos ha servido para la explotación de la cantera de la obra. También en la ladera izquierda se observaron, en esa zona de aguas abajo, algunos paquetes de estratos separados de la ladera y que la erosión del río irá socavando hasta arrastrarlos definitivamente. 

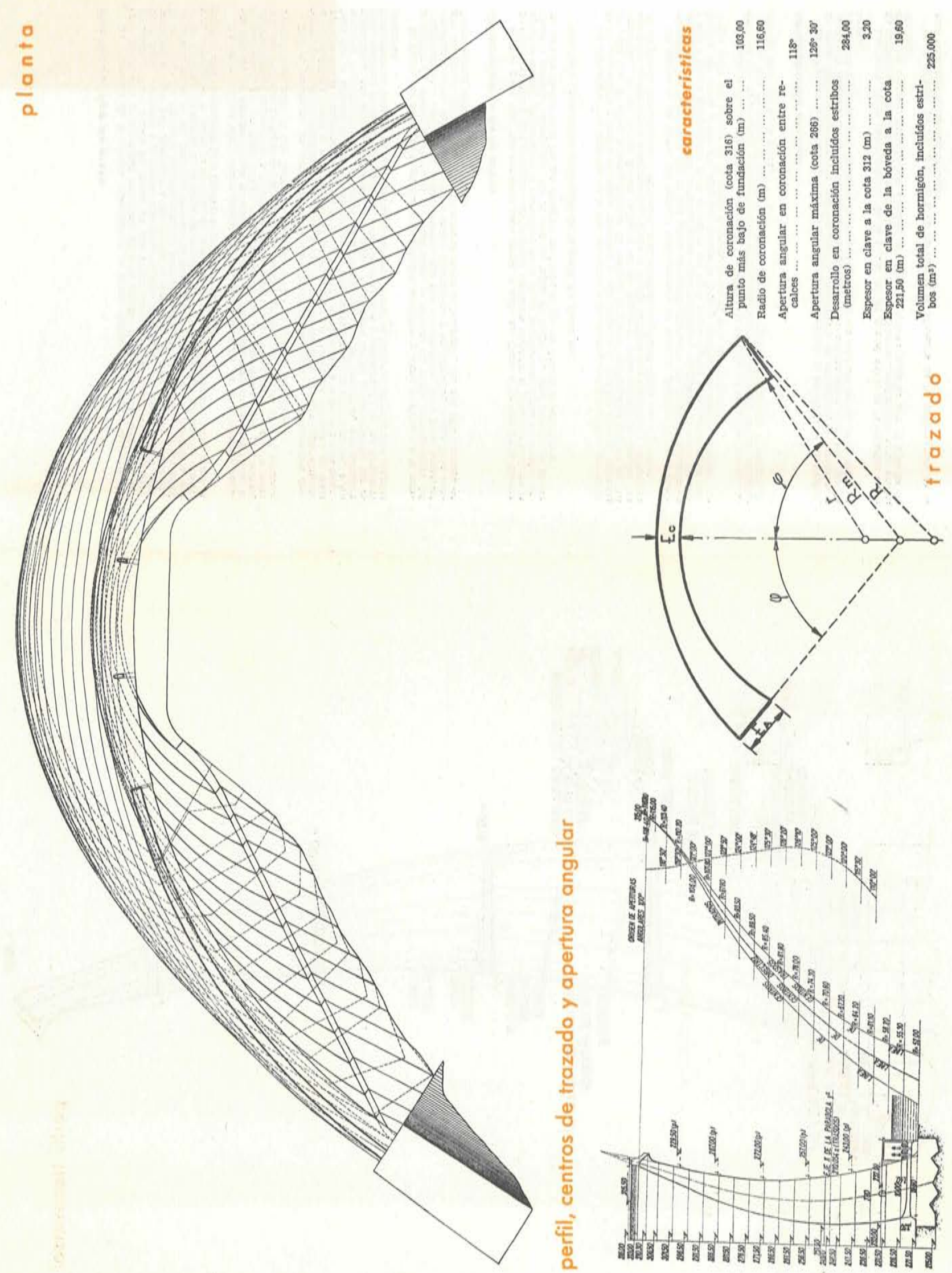

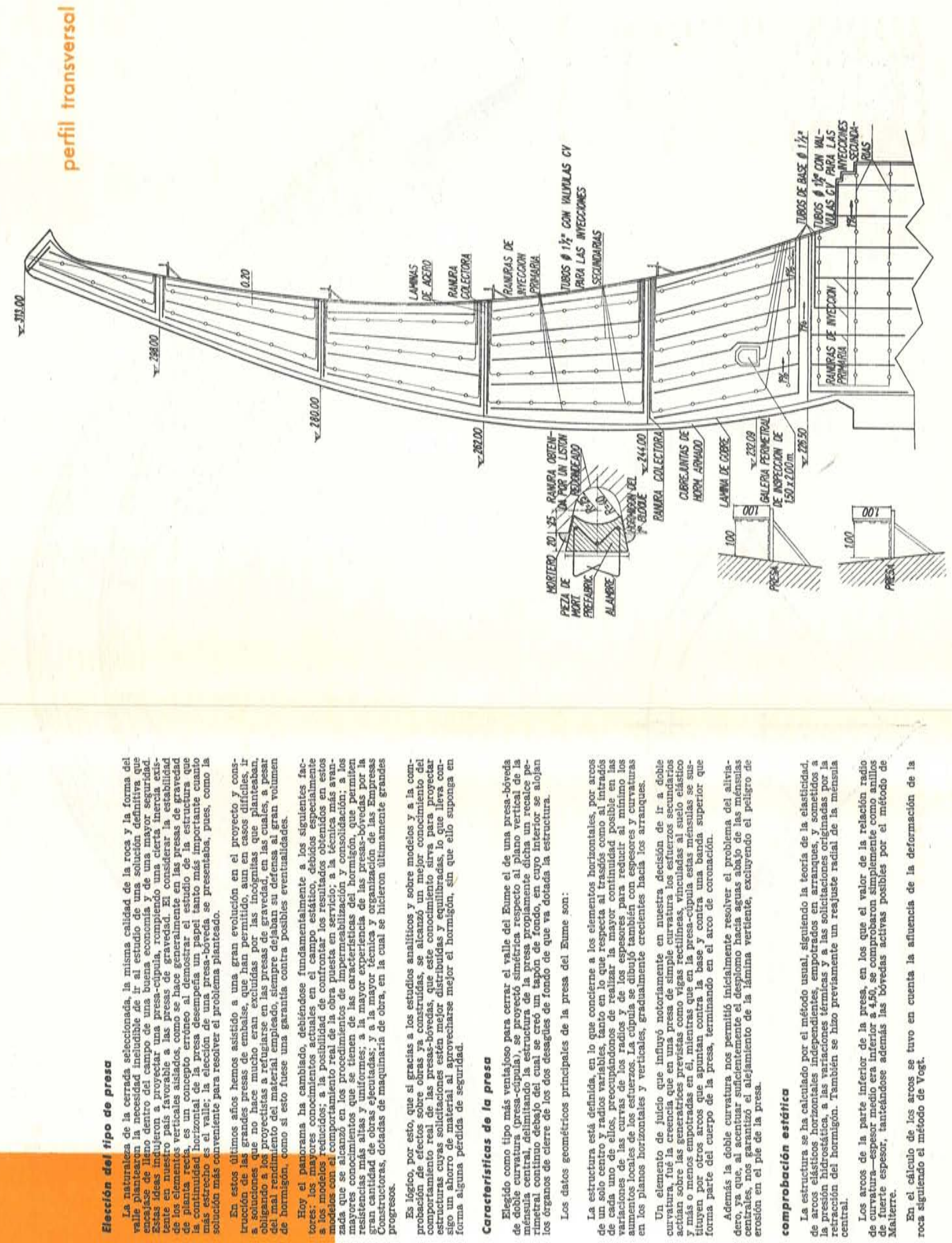

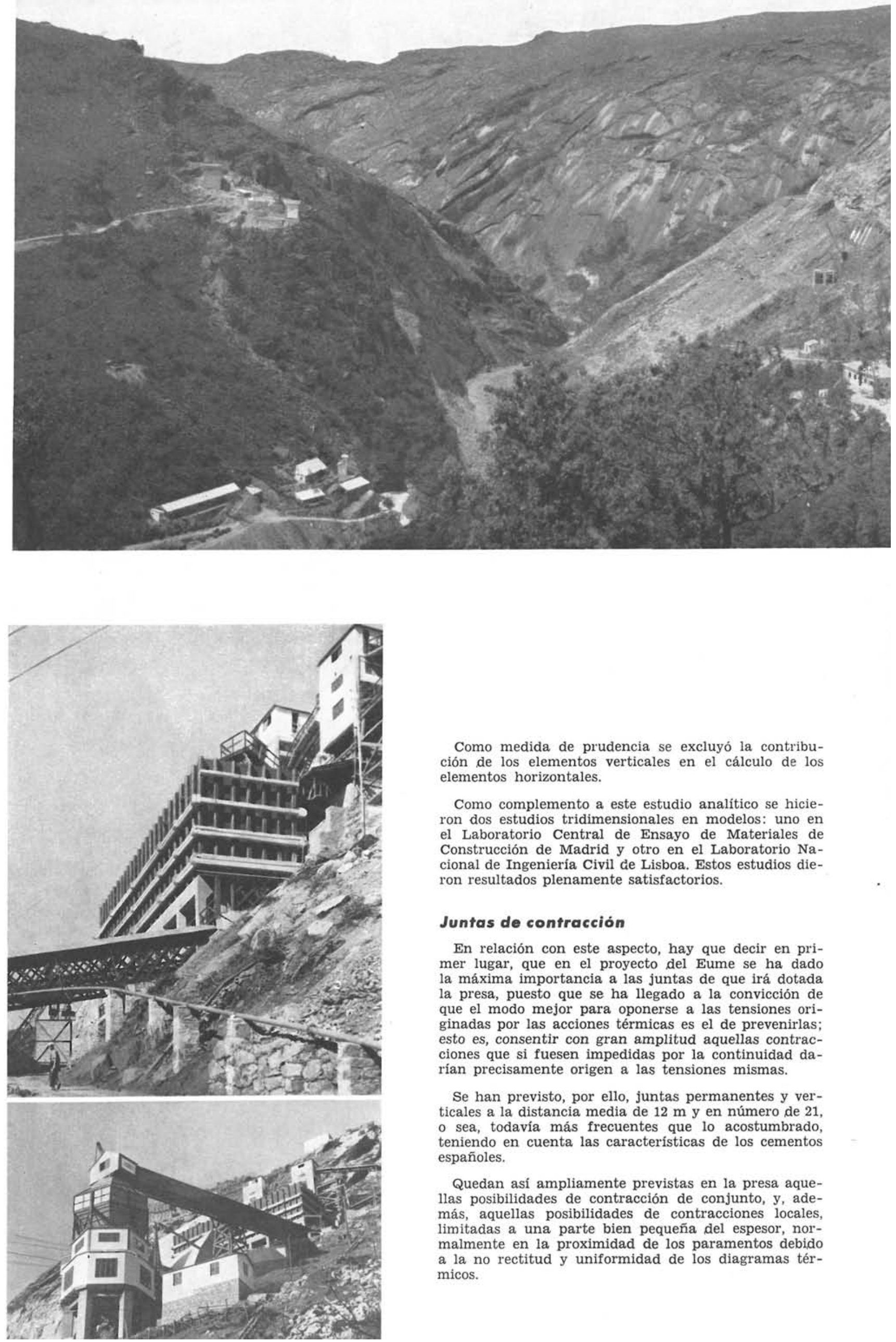

Como medida de prudencia se excluyó la contribución de los elementos verticales en el cálculo de los elementos horizontales.

Como complemento a este estudio analítico se hicieron dos estudios tridimensionales en modelos: uno en el Laboratorio Central de Ensayo de Materiales de Construcción de Madrid y otro en el Laboratorio Nacional de Ingeniería Civil de Lisboa. Estos estudios dieron resultados plenamente satisfactorios.

\section{Juntas de contracción}

En relación con este aspecto, hay que decir en primer lugar, que en el proyecto del Eume se ha dado la máxima importancia a las juntas de que irá dotada la presa, puesto que se ha llegado a la convicción de que el modo mejor para oponerse a las tensiones originadas por las acciones térmicas es el de prevenirlas; esto es, consentir con gran amplitud aquellas contracciones que si fuesen impedidas por la continuidad darían precisamente origen a las tensiones mismas.

Se han previsto, por ello, juntas permanentes y vertícales a la distancia media de $12 \mathrm{~m}$ y en número de 21 , - sea, todavía más frecuentes que lo acostumbrado, teniendo en cuenta las características de los cementos españoles.

Quedan así ampliamente previstas en la presa aquellas posibilidades de contracción de conjunto, y, además, aquellas posibilidades de contracciones locales, limitadas a una parte bien pequeña del espesor, normalmente en la proximidad de los paramentos debido a la no rectitud y uniformidad de los diagramas térmicos. 


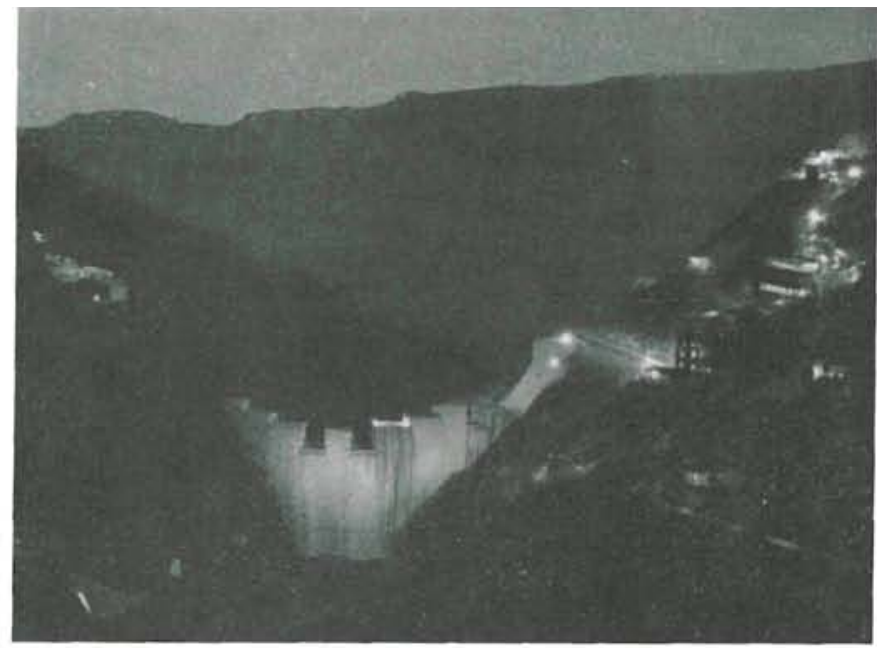

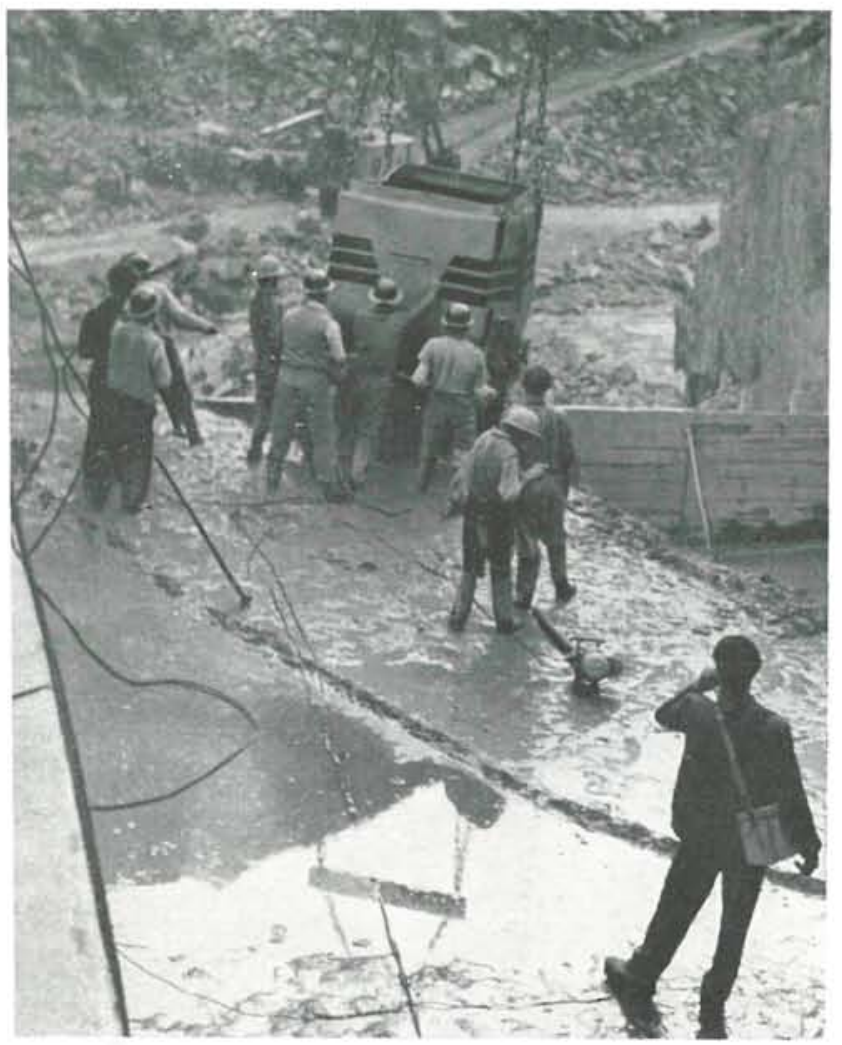

\section{Aliviadero}

La cuenca vertiente del río Eume hasta el emplazamiento de la presa tiene una superficie total de 500 kilómetros cuadrados. La lluvia media anual es de $1.200 \mathrm{~mm} / \mathrm{m}^{2}$, que, unida a un elevado coeficiente de escorrentía debido a la impermeabilidad del terreno origina una aportación media anual de $400 \times 10^{6} \mathrm{~m}^{3}$ de agua con un caudal medio de $13 \mathrm{~m}^{3} / \mathrm{s}$. Las máximas avenidas, deducidas según el estudio del río y de otros similares situados en la cuenca atlántica, se fijaron en $600 \mathrm{~m}^{3} / \mathrm{s}$.

Dada la pequeña cuantía de estas avenidas, después de una serie de tanteos, entre la solución de un aliviadero en pozo con una embocadura en forma de "Morning glory" o un aliviadero libre en coronación, nos decidimos por esta última solución. Esta elección fué debida al factor económico, a la facilidad constructiva y a los resultados de las prospecciones sísmicas realizadas en el cauce en la zona de vertido, en la cual se obtuvieron módulos de elasticidad de la roca del orden de $\operatorname{los} 500.000 \mathrm{~kg} / \mathrm{cm}^{2}$.

El vertedero quedó definido por tres vanos de 20 metros de luz con una altura de 2,50 metros de lámina vertiente, que en caso de emergencia puede alcanzar los 3,00 metros. Estas tres láminas caen en un cuenco amortiguador de solera parabólica con vértice en la cota 220 , cerrada por una contra-ataguía de planta recta y coronación horizontal de cota 227.

El aliviadero es libre sin compuertas, a causa del escaso valor de los terrenos afectados por la sobreelevación de la lámina en caso de máximas avenidas sobre el nivel normal del embalse.
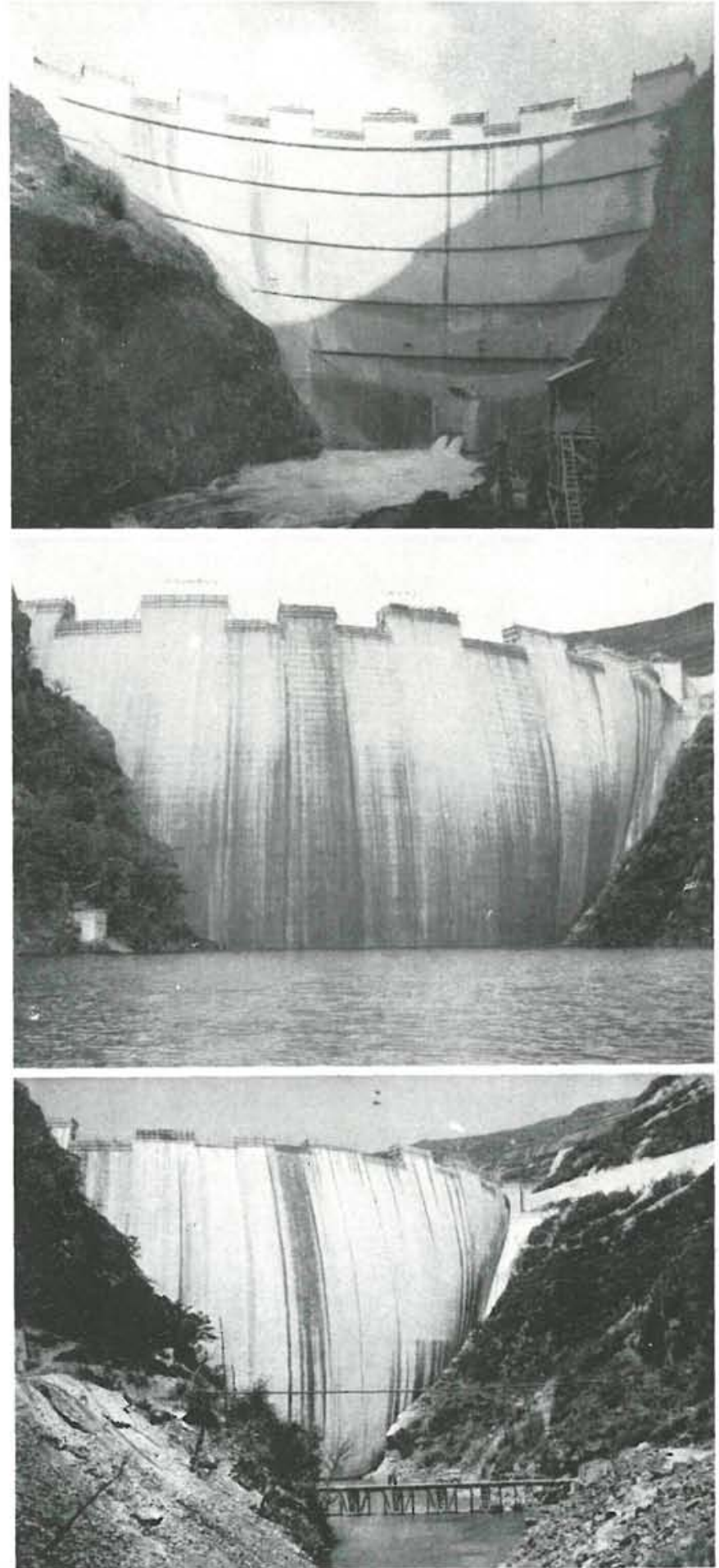
Para la comprobación de este aliviadero se realizaron varios ensayos sobre un modelo a escala $1 / 60$, estudiándose su régimen de funcionamiento, el perfil del mismo, abarcándose la forma de la lámina vertiente, la capacidad de desagüe y el despegue o adherencia de aquélla sobre el paramento de aguas abajo de la presa.

La solución definitiva conseguida es satisfactoria, comprobándose que las presiones máximas en el cuenco no sobrepasan los 23 metros, y que no existen prácticamente presiones negativas.

El funcionamiento de vertido es bueno aun con los caudales más altos, quedando la agitación limitada al interior del cuenco, sin peligro ninguno de erosión para las laderas y cauce.

Toda la solera del cuenco va drenada con tubos de fibrocemento de 6 pulgadas, con salida al exterior para evitar efectos de subpresiones en el peor de los casos.

\section{Desagües de fondo}

Para complementar el aliviadero y para cumplir la misión de vaciar el embalse en un momento determinado, la presa va dotada de dos desagües de fondo, de $1,40 \mathrm{~m}$ de diámetro, cerrados cada uno de ellos por dos compuertas gemelas de tipo americano, de $1,00 \times 1,50 \mathrm{~m}$, construídos en acero moldeado y accionadas por gatos hidráulicos. La carga total sobre el centro de las compuertas es de $92,00 \mathrm{~m}$ de altura.

\section{Túnel de conducción}

El túnel de conducción del Salto del Eume tiene una longitud de 2.839 metros y 3,30 metros de diámetro.

El carácter predominante del terreno que atraviesa, es el de pizarras con laminación más bien vertical, cortando al eje del túnel con un ángulo pequeño, por lo que se llegó a un revestimiento total del túnel.

Este revestimiento garantiza: la estabilidad mecánica; la impermeabilidad; la inalterabilidad, y permitió obtener la máxima economía.

Los diversos tipos de revestimientos empleados, según la naturaleza del terreno, son los siguientes:

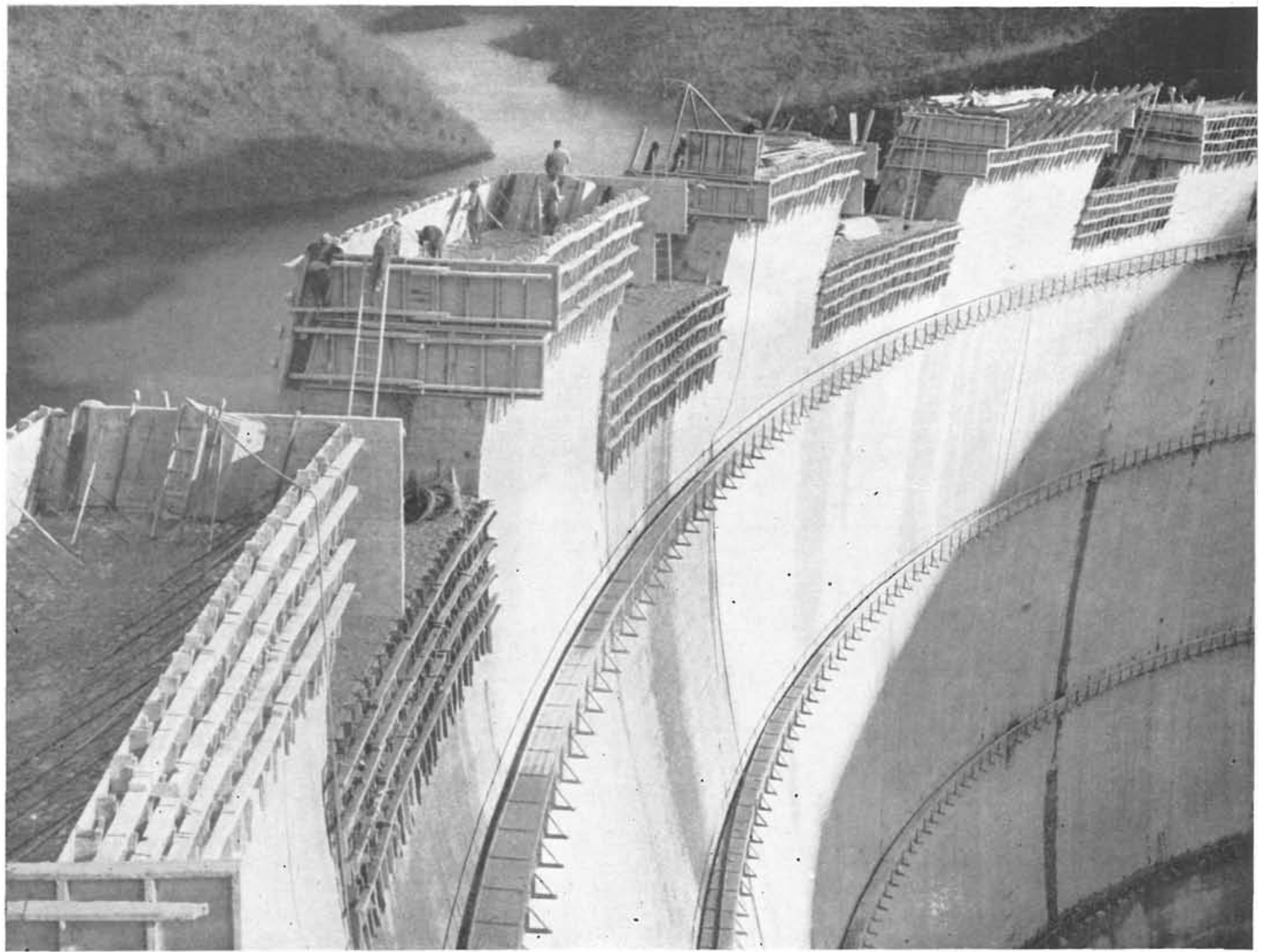




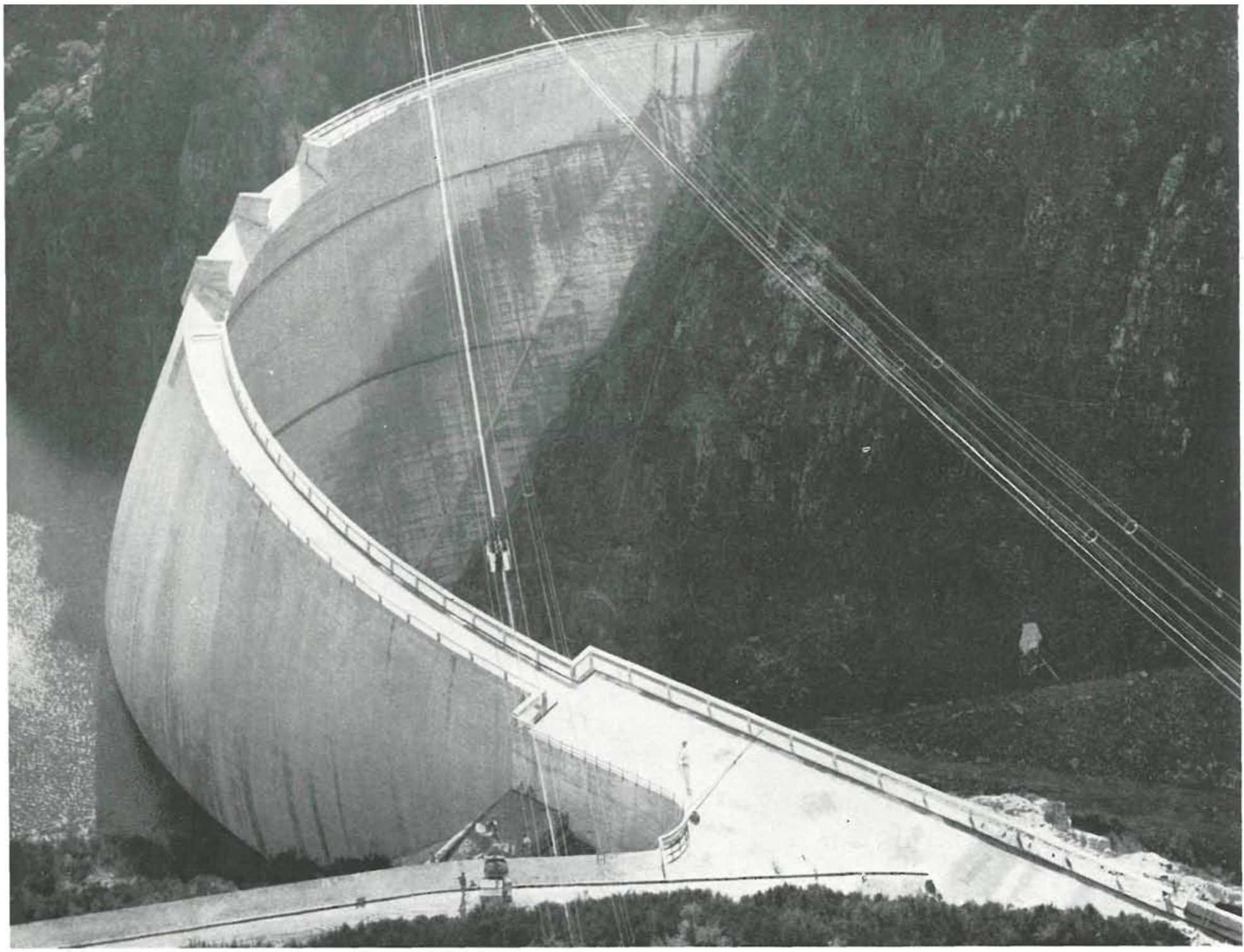

\begin{tabular}{|c|c|c|c|}
\hline $\begin{array}{l}\text { Módulo elástico } \\
\text { en lo pared } \\
\left(\mathrm{kg}^{\prime} / \mathrm{cm}^{2}\right)\end{array}$ & $\begin{array}{l}\text { Altura de la } \\
\text { cobertura } \\
(\mathrm{m})\end{array}$ & $\begin{array}{c}\text { Permeabilidad } \\
\text { natural de la roca } \\
\text { (l/ } / \mathrm{min})\end{array}$ & Tipo de revestimiento propuesto \\
\hline $\begin{array}{l}\text { Superior a } 150.000 \\
\mathrm{~kg} / \mathrm{cm}^{2} \text {. }\end{array}$ & Superior a $75 \mathrm{~m}$. & $\begin{array}{l}\text { Pérdidas inferiores } \\
\text { a } 4 \mathrm{l} \text { /minutos. }\end{array}$ & $\begin{array}{l}\text { Revestimiento simple de } 3,44 \mathrm{~m} \text { de diámetro interior. } \\
\text { Inyección de relleno a } 5 \mathrm{~kg} / \mathrm{cm}^{2} \text {. } \\
\text { Diámetro interior: } 3,44 \mathrm{~m} \text {. }\end{array}$ \\
\hline $\begin{array}{l}\text { Superior a } 25.000 \text {, } \\
\text { pero inferior a } \\
150.000 \text {. }\end{array}$ & Superior a $40 \mathrm{~m}$. & $\begin{array}{c}\text { Superiores a } 4 \\
1 / \text { minutos. }\end{array}$ & $\begin{array}{l}\text { Revestimiento simple de } 3,44 \mathrm{~m} \text { de diámetro interior. } \\
\text { Inyecciones de relleno a } 5 \mathrm{~kg} / \mathrm{cm}^{2} \text {, o inyección de li- } \\
\text { gazón } 15 \mathrm{~kg} / \mathrm{cm}^{2} \text {. }\end{array}$ \\
\hline & Idem. & Idem. & Diámetro interior: $3,44 \mathrm{~m}$ \\
\hline Idem. & Idem. & Idem. & $\begin{array}{l}\text { Como el anterior, pero con anillo de gunita armada } \\
\text { con redondos de acero de } 25 \mathrm{~mm} \text { diámetro. }\end{array}$ \\
\hline Idem. & Idem. & Idem. & Diámetro interior: $3,30 \mathrm{~m}$. \\
\hline Superior a 25.000 . & $\begin{array}{l}\text { Comprendidos en- } \\
\text { tre } 40 \text { a } 25 \mathrm{~m} \text {. }\end{array}$ & Idem. & $\begin{array}{l}\text { Como el anterior, pero con anillo de gunita armado } \\
\text { con redondos de acero de } 30 \mathrm{~mm} \text { diámetro. }\end{array}$ \\
\hline Inferior a 25.000 . & Superior a $25 \mathrm{~m}$. & Idem. & Diámetro interior: $3,25 \mathrm{~m}$. \\
\hline Todos los casos. & Inferior a $25 \mathrm{~m}$. & Idem. & $\begin{array}{l}\text { Blindaje calculado para la carga total sin participación } \\
\text { de la roca. }\end{array}$ \\
\hline
\end{tabular}




\section{Compuerta de foma}

Como elementos inherentes al túnel de conducción se dispuso a la entrada del mismo la toma de agua, constituída por una estructura de hormigón cerrada por rejilla metálica.

Dicha toma puede quedar cerrada por una compuerta de $2,60 \times 3,50 \mathrm{~m}$, equivalente a la sección del túnel. Esta compuerta es del tipo "oruga" dada la carga elevada que actúa sobre el tablero de la misma que así se transmite uniformemente sobre los caminos de rodamiento al hormigón que constituye la estructura.

La compuerta se utilizará normalmente como órgano de aislamiento destinado a permitir la visita y conservación de la galería, permitiendo el cierre eventual con toda la carga en caso de accidente aguas abajo de la toma. Esta maniobra podrá ser provocada a distancia desde la Central o desde la cámara de maniobra de la propia compuerta. La apertura, en cambio, se efectúa después de llenar la galería, equilibrando así las presiones de aguas arriba y abajo de la compuerta. El llenado se hace abriendo $10 \mathrm{~cm}$ esta compuerta.

\section{Chimenea de equilibrio}

En el tramo final del túnel va dispuesta en el Salto del Eume una chimenea de equilibrio, que tiene la finalidad clásica de este elemento regulador y cuyas dimensiones son $4,50 \mathrm{~m}$ de diámetro para la chimenea propiamente dicha, diámetro que garantiza la estabilidad inicial según el criterio de Thoma.

La cámara superior tiene un diámetro de $16,00 \mathrm{~m}$ y la máxima oscilación en la misma para el cierre brusco de turbinas es de 6,70 metros. La hipótesis efectuada en el cálculo realizado para dimensionar esta cámara, hecho por diferencias finitas, fué el pasar del caudal máximo de $Q_{0}=26,200 \mathrm{~m}^{3} / \mathrm{s}$ a $Q_{1}=0,00 \mathrm{me}-$ tros cúbicos/segundo.

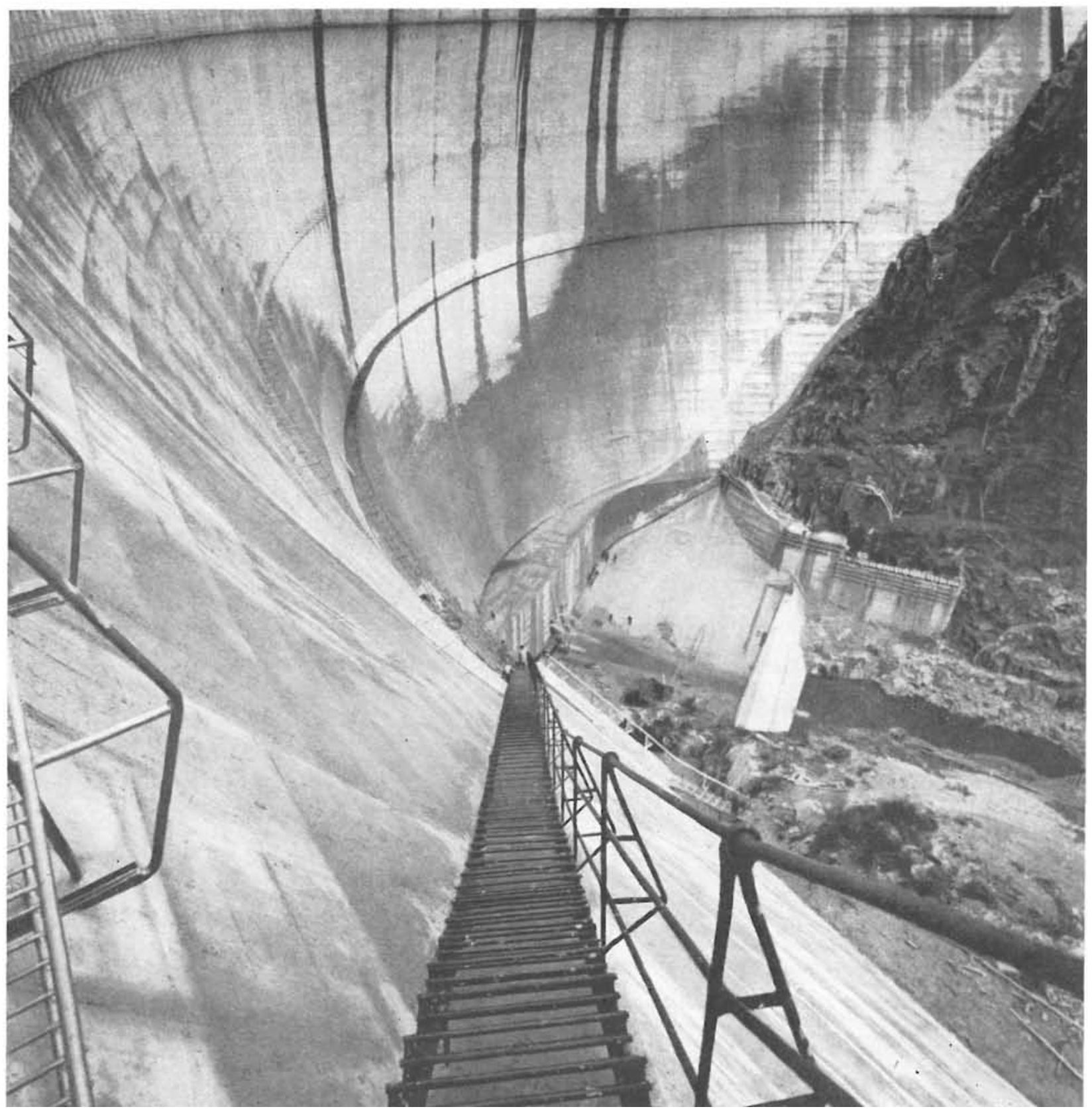




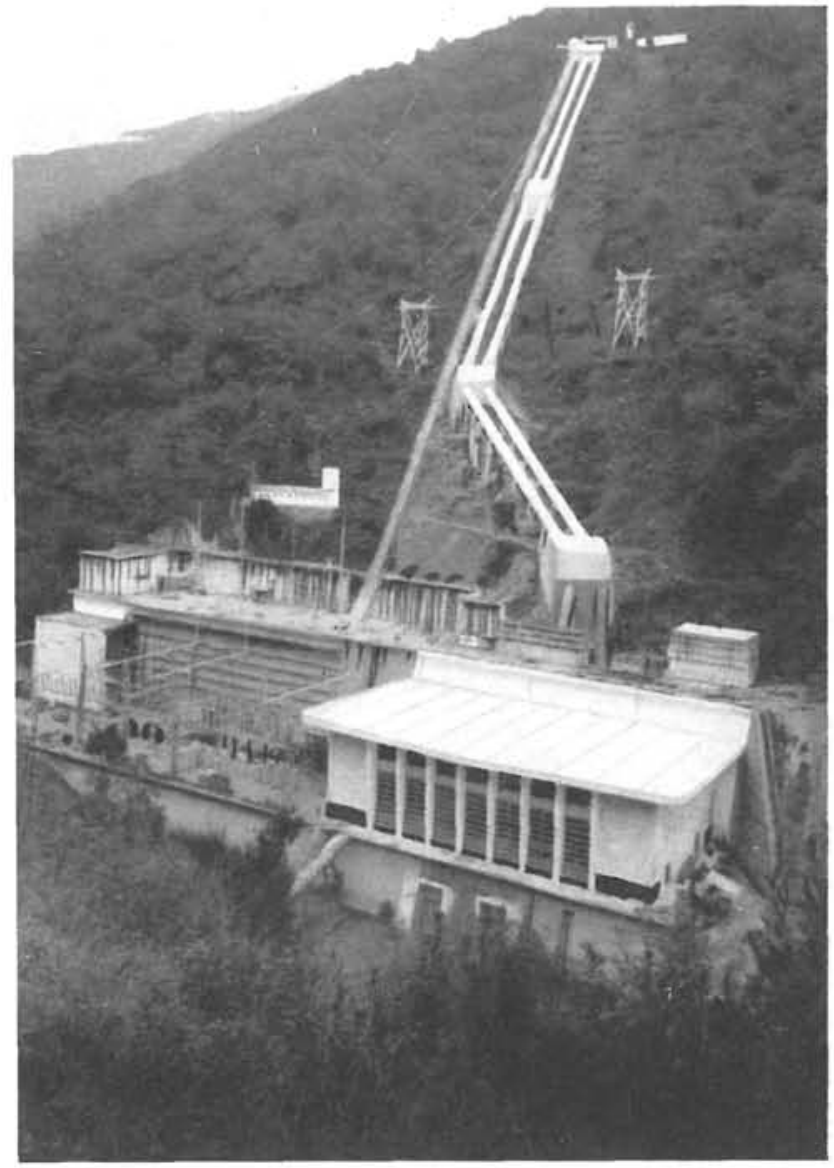

Para el dimensionamiento de la cámara inferior se partió de la hipótesis de un caudal de $Q_{0}=13,100 \mathrm{~m}^{2} / \mathrm{s}$ al caudal necesario para la máxima carga de la Central, o sea, $Q_{1}=26,200 \mathrm{~m}^{3} / \mathrm{s}$.

El descenso máximo quedó en este caso definido en $7,00 \mathrm{~m}$ para el golpe de ariete negativo señalado.

La circunstancia especial de esta chimenea es que la cámara inferior tiene un doble ramal de acometida al túnel de conducción para atacar desde aguas arriba este túnel de conducción, ya que en la sección comprendida entre los dos enlaces de la chimenea con él se originó durante la construcción del mismo un desprendimiento que era difícil de salvar con la perforación que se estaba efectuando desde la boca de salida de dicho túnel.

A partir de esta chimenea, la galería lleva un blindaje hasta la caseta de las válvulas de mariposa de que van dotadas en sus entradas las dos tuberías, tuberías de palastro soldado con $2,00 \mathrm{~m}$ de diámetro y $310 \mathrm{~m}$ de longitud, que alimentan la Central.

\section{Central}

Su equipo eléctrico está constituído por dos grupos, con turbinas tipo Francis de $37.500 \mathrm{CV}$ cada una y alternadores de $32.000 \mathrm{kVA}$. La tensión de generación de las máquinas es de 11.000 voltios, la cual se eleva a 132.000 voltios mediante un transformador por grupo de $32.000 \mathrm{kVA}$ de potencia.

Esta Central producirá 180 millones de $\mathrm{kWh}$ anuales, completamente regulados. $\mathrm{Y}$ por su ubicación cercana a los grandes centros de consumo de La Coruna y El Ferrol constituye para FENOSA una nueva fuente de energía de particular importancia, que servirá para alimentar una serie de nuevas industrias que se están emplazando en la provincia de La Coruña.

Fotor- M. G. MOYA Y GAMA
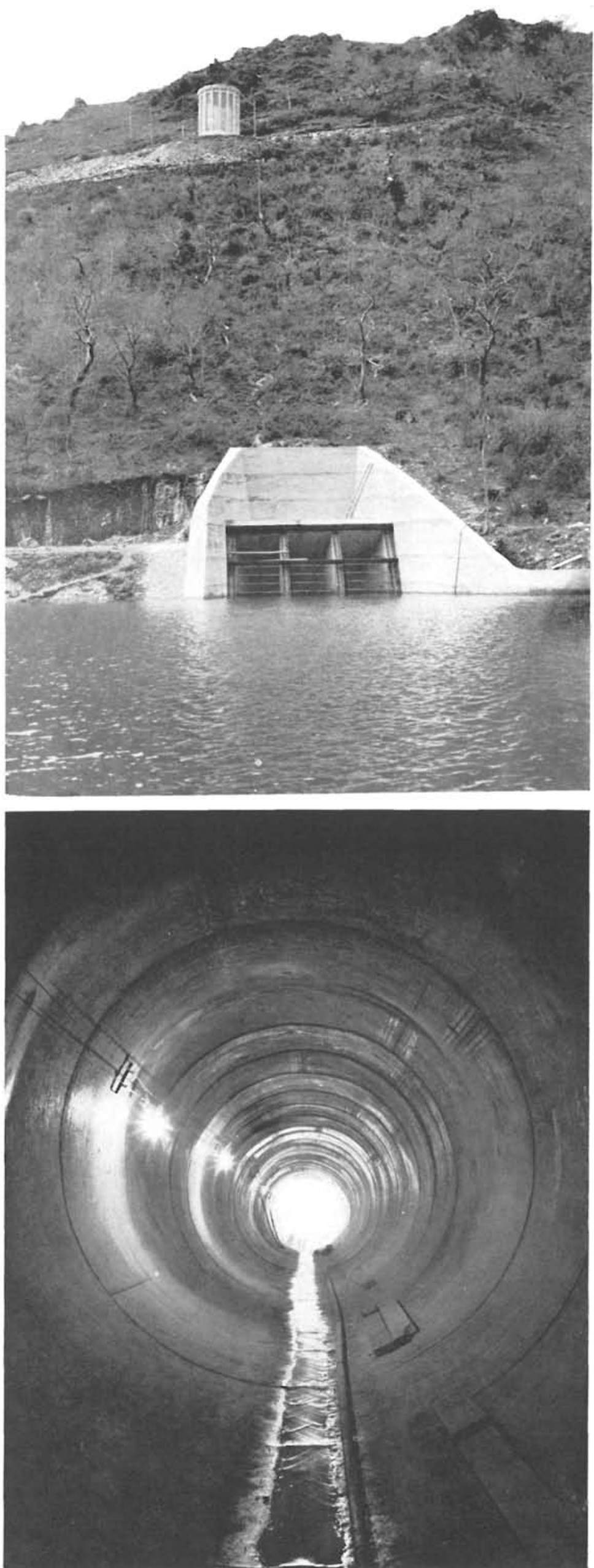